\title{
Effect of bee pollen and propolis (bee glue) on growth performance and biomarkers of heat stress in broiler chickens reared under high ambient temperature
}

\author{
S.M. Hosseini ${ }^{1}$, M. Vakili Azghandi ${ }^{2}$, S. Ahani ${ }^{2}$ and R. Nourmohammadi ${ }^{2,3}$ \\ ${ }^{1}$ University of Birjand, Depatment of Animal Science, Faculty of Agriculture, Birjand, Iran \\ ${ }^{2}$ Young Researchers and Elites Club, Birjand Branch, Islamic Azad University, Birjand, Iran
}

KEY WORDS: bee glue, bee pollen, broiler, heat stress, heat stress markers, performance

Received: 17 March 2015

Revised: 24 February 2016

Accepted: $\quad 7$ March 2016

${ }^{3}$ Corresponding author:

e-mail: nourmohammadi.61@gmail.com

\begin{abstract}
This study investigated the supplemental effects of bee pollen (BP) and propolis (bee glue; BG) on broiler performance, intestinal morphometry, haematological profile and biomarkers of heat stress in broilers reared under high ambient temperature. Two hundred and forty one-day-old male broiler chickens were divided into 4 treatment groups: control; BP - supplemented with $20 \mathrm{~g}$ of $B P \cdot \mathrm{kg}^{-1}$ of feed; $B G$ - supplemented with $3 \mathrm{~g}$ of $B G \cdot \mathrm{kg}^{-1}$ of feed; and $B P+B G$ - supplemented with $20 \mathrm{~g}$ of $\mathrm{BP} \cdot \mathrm{kg}^{-1}+3 \mathrm{~g}$ of $\mathrm{BG} \cdot \mathrm{kg}^{-1}$. It was estimated that dietary BP and BG improved average daily gain and average daily feed intake of broilers particularly during the starter period $(P<0.05)$. The relative weights of spleen and bursa of Fabricius were higher in groups fed supplemented diets when compared to the control group $(P<0.05)$. Biomarkers of heat stress including the circulating heterophil: lymphocyte ratio, creatine kinase level and mRNA expression of $70 \mathrm{kD}$ heat shock protein (HSP70) levels in breast muscle were decreased in supplemented birds. In birds fed diets with BP and BG addition, crypts were deeper and villus:crypt ratios were higher in the jejunum segment $(P<0.05)$. The obtained results suggest that the dietary use of both $B P$ and $B G$ as a feed additive may offer a practical nutritional strategy in high temperature environment to prevail the harmful effects of heat stress in broiler.
\end{abstract}

\section{Introduction}

In tropical and subtropical regions, heat stress (HS) is considered as a critical problem in the poultry industry. High ambient temperatures not only cause heavy economic losses in this industry by reducing feed consumption and increasing mortality rate but have negative influence on meat quality (Chiang et al., 2008), too. Also, HS has been associated with an increased number of heterophils and decreased number of lymphocytes. In addition, HS increases heat shock proteins expression in skeletal and cardiac muscles, which may enhance the tolerance to stress and increase the survival rate of stressed cells (Kamboh et al., 2013).

Recent studies showed that supplementation of natural antioxidants is a suitable strategy to minimize the deleterious effects of heat stress in broiler chickens. Propolis (bee glue; BG), which exhibits a strong antioxidant properties, was reported to improve the growth performance and egg quality in birds reared under high ambient temperatures (Seven, 2008). BG is a resinous and balsamic material collected by worker honeybees (Apis mellifera L.) from tree buds, sap 
flows or other botanical sources, and mixed with their wax and salivary enzymes. It has strong antibacterial (Bankova et al., 2000), antioxidant (Banskota et al., 2000), antiviral (Vynograd et al., 2000), and anti-inflammatory (Sforcin, 2007), antifungal and immunostimulatory properties (Bankova et al., 2000), and cytostatic and hepatoprotective activities (Banskota et al., 2000). Due to the presence of important compounds such as fla-vonoids, phenolic constituents and terpenoid, the use of BG in broiler diet was recommended as a way to minimize the negative effects of HS (Sforcin and Bankova, 2011). It was proved that flavonoids show an antioxidant activity towards oxidants in the cell membrane (Sforcin, 2007).

Bee pollen (BP) is a natural product, which is collected by honeybees from plants. The BP is created in the male sexual organ of the flower (anthers) with the purpose of fertilizing the stigma. It is the main source of proteins for bees (Wang et al., 2007). Similarly to BG, BP is a rich source of flavonoids, carotenoids and phytosterols (Xu et al., 2009). In addition, BP is able to improve gastrointestinal health, protect kidney, and decrease blood lipid metabolites and creatinine in broilers (Attia et al., 2014).

To the best of our knowledge, the supplemental effects of BP and BG in broilers reared under high ambient temperature are largely unrevealed. Therefore, the aim of this study was to investigate the effect of dietary BP or BG alone and in combination on performance, relative organs weight, haematological parameters, intestinal morphometry, creatine kinase (CK) and heat shock protein 70 mRNA levels (HSP70) in broiler chickens.

\section{Material and methods}

\section{Experimental chickens}

Two hundred and forty male broiler chickens ( $49.4 \pm 0.8 \mathrm{~g}$, Ross 308 , one-day old) were used in this study. All chickens were kept in the uniform light conditions for $24 \mathrm{~h}$. Birds had ad libitum access to feed and water during the experimental period. The room temperature was maintained at $35^{\circ} \mathrm{C}$ on day 1 , then the temperature was gradually reduced to $33^{\circ} \mathrm{C}$ on day 3 , which was maintained during the 42-day experiment to generate the high ambient temperature. The trial was conducted in two phases: starter (days 1-21) and finisher (days 22-42). The animal care protocol in this experiment was approved by the Animal Ethics Committee of the Birjand University.

\section{Preparation of bee pollen (BP) and bee glue (BG)}

The BP and BG were mainly collected by the honeybee Amygdalus scoparia L. in the spring season. The BP was ground to pass through a $1-\mathrm{mm}$ screen and then mixed to the feed. The handcollected BG was kept desiccated in the dark until the processing. Than it was ground and a $30 \%$ ethanolic extract was prepared in sterile conditions ( $30 \mathrm{~g}$ of BG completing the volume to $100 \mathrm{ml}$ with $70 \%$ ethanol), in the absence of bright light, at room temperature by shaking moderately. After filtration, the final concentrations were calculated to obtain the dry weight of the solution $\left(120 \mathrm{mg} \cdot \mathrm{ml}^{-1}\right)$.

\section{Experimental design and diets}

The experiment was performed as a completely randomized design with 4 treatments and 5 replicates of 12 chickens kept in cages. The 4 dietary treatments were as follows: control; BP - supplemented with $20 \mathrm{~g}$ of $\mathrm{BP} \cdot \mathrm{kg}^{-1}$ of feed; $\mathrm{BG}$ - supplemented with $3 \mathrm{~g}$ of $\mathrm{BG} \cdot \mathrm{kg}^{-1}$ of feed; and $\mathrm{BP}+\mathrm{BG}-$ supplemented with $20 \mathrm{~g}$ of $\mathrm{BP} \cdot \mathrm{kg}^{-1}+3 \mathrm{~g}$ of BP $\cdot \mathrm{kg}^{-1}$. Basal diets were formulated to meet or exceed the Ross 308 broiler nutrition specifications for macro- and micronutrients (Table 1) (NRC, 1994). All diets were fed in a mash form.

Table 1. Basal diet composition in starter and finisher periods

\begin{tabular}{|c|c|c|}
\hline Indices & $\begin{array}{l}\text { Starter period } \\
\text { (days } 0-21 \text { ) }\end{array}$ & $\begin{array}{l}\text { Finisher period } \\
\text { (days 22 - 42) }\end{array}$ \\
\hline \multicolumn{3}{|l|}{ Ingredients, $\mathrm{g} \cdot \mathrm{kg}^{-1}$} \\
\hline maize $\left(8 \% \mathrm{CP}^{1}\right)$ & 596.2 & 639.3 \\
\hline soyabean meal (48\% CP) & 308.3 & 265.1 \\
\hline soyabean oil & 28.2 & 30.7 \\
\hline meat meal (55\% CP) & 40.0 & 40.0 \\
\hline dicalcium phosphate & 10.8 & 10.3 \\
\hline calcium carbonate & 7.0 & 5.7 \\
\hline $\mathrm{NaCl}$ & 4.4 & 4.1 \\
\hline vitamin-mineral premix² & 4.5 & 4.1 \\
\hline choline chloride (70\%) & 0.6 & 0.7 \\
\hline \multicolumn{3}{|l|}{ Calculated analysis } \\
\hline metabolizable energy, $\mathrm{MJ} \cdot \mathrm{kg}^{-1}$ & 3100 & 3200 \\
\hline available phosphorus, $\mathrm{g} \cdot \mathrm{kg}^{-1}$ & 4.1 & 4.1 \\
\hline lysine, $\mathrm{g} \cdot \mathrm{kg}^{-1}$ & 12.2 & 11.0 \\
\hline methionine, $\mathrm{g} \cdot \mathrm{kg}^{-1}$ & 5.8 & 5.3 \\
\hline methionine + cystine, $\mathrm{g} \cdot \mathrm{kg}^{-1}$ & 9.5 & 8.8 \\
\hline \multicolumn{3}{|l|}{ Calculated composition, $\mathrm{g} \cdot \mathrm{kg}^{-1}$} \\
\hline crude protein & 218 & 201 \\
\hline calcium & 9.5 & 9.1 \\
\hline total phosphorus & 6.9 & 6.9 \\
\hline crude fat & 60.0 & 60.0 \\
\hline
\end{tabular}

${ }^{1} \mathrm{CP}$ - crude protein; ${ }^{2}$ provided per $\mathrm{kg}$ of diet; IU: vit. A 9000, vit $\mathrm{D}_{3} 2000$, vit. E 18; mg: Cu 10, Fe 50, Mn 100, Zn 85, Se 0.2, I 1, vit $\mathrm{K} 2$, thiamine 1.8 , riboflavin 6.6 , pyridoxine 3.0 , vit. $\mathrm{B}_{12} 15$, niacin 30 , pantothenic acid 10, folic acid 1.25 , choline 500 and biotin 0.1 


\section{Chicken performance}

On day 21 and 42, the body weight (BW) and feed intake were measured after $4 \mathrm{~h}$ feed withdrawal to determine an average daily gain (ADG), average daily feed intake (ADFI) and feed conversion ratio (FCR).

\section{Size of different organs}

On 42 day of life, two randomly chosen birds per replicate ( 10 birds per treatment) were randomly selected and after 4 hour feed withdrawal slaughtered by cutting jugular veins and carotid arteries. The weights of the pancreas, liver, gizzard, heart, spleen and bursa were recorded. Then organs were cleaned with physiological saline solution, dried with filter paper and weighed. The weight of each organ was expressed in relation to body weight before slaughter $\left(\mathrm{g} \cdot 100 \mathrm{~g}^{-1} \mathrm{BW}\right)$.

\section{Biomarkers analysis}

For analysis of the heat stress biomarkers, including circulating heterophil:lymphocyte (H:L) ratio, $2 \mathrm{ml}$ blood samples from 10 broilers per treatment were collected and put in tubes containing anticoagulant heparin (Fisher HealthCare, Houston, TX, USA), kept on ice and immediately used for haematological analysis. Haematological analysis was conducted to measure the levels of heterophils and lymphocytes by using an automatic haematological analyser (Sysmex XE-2100 ${ }^{\mathrm{TM}}$ Automated Hematology System; Sysmex America, Inc., Lincolnshire, IL, USA). These concentrations were also used to calculate the $\mathrm{H}: \mathrm{L}$ ratio index.

The breast (Pectoralis major) muscles without skin and adipose tissues were collected from 10 broilers per treatment, quickly snap-frozen in liquid nitrogen and then used to analyse the creatine kinase (CK) level using commercially available colorimetric kit (Nanjing Jiancheng Bioengineering Institute, Nanjing, China). The result was calculated per $\mathrm{mg}$ of protein measured in accordance to Kamboh et al. (2013) method.

In the muscles, the HSP70 mRNA expression level was also analysed using Real-Time RT-PCR method according to procedure discribed by Hao et al. (2012). The chicken HSP70 gene sequence deposited in GenBank under the accession number J02579 was used as nucleotide sequence in the current research.

\section{Intestinal morphology measurements}

Ten slaughtered birds per treatment were randomly used for the intestinal morphometery conducted in accordance to Yu et al. (1998) method. The digestive tract with contents was removed and fragments of approximately $5 \mathrm{~cm}$ were obtained from the middle following segments of the small intestine: the duodenum (from the pylorus to the distal portion of the duodenal loop), the jejunum (from the distal portion of the duodenal loop to Meckel's diverticulum) and the ileum (the anterior portion of the ileocecal junction) to evaluate the intestinal morphology. Then, each segment fragments were placed on polystyrene sheets, opened longitudinally, washed in saline solution, fixed in $10 \%$ formaldehyde solution, dehydrated and embedded in paraffin. Thin sections from each segment were cut $(5 \mu \mathrm{m}$ thickness) and stained with haematoxylin and eosin according to Luna (1968). Measurements for villus lengths were taken from the tip of the villus to the valley between individual villi, and measurements for crypt depth were taken from the valley between individual villi to the basolateral membrane. Villus length, crypt depth and thickness of epithelium were measured at $100 \times$ magnification using computer software (Sigma Scan, Jandel Scientific, San Rafael, CA, USA), and the data were used to calculate the villus length: crypt depth ratio. The length of 30 villi and the depth of 30 crypts were measured from each segment and replicate, and the means were analysed statistically.

\section{Statistical analyses}

Data was analysed by ANOVA using the General Linear Model (GLM) procedure of SAS (SAS, 2006). The corresponding means were compared by Tukey-Kramer's test and statistical differences were declared at $P<0.05$.

\section{Results}

In the starter ( $1-21$ day of life) and overall (1-42 day of life) periods, the average daily gain (ADG) and average daily feed intake (ADFI) were influenced by bee pollen (BP) or bee glue (BG) supplementation in comparison to the control diet (Table 2). There was also a significant increase $(P<0.05)$ in ADG and ADFI when both BP and BG were added to the basal diet. When compared to the control group, ADG and ADFI of BP group were increased $(P<0.05)$ by 15.6 and $15.3 \%$, respectively, and also ADG and ADFI of BG group were increased $(P<0.05)$ by 15.0 and $14.3 \%$, respectively; however there was observed no influence on feed conversion ratio (FCR) in the starter phase. Also, when $\mathrm{BP}$ and BG were supplemented together, ADG and ADFI were significantly increased $(P<0.05)$ by 14.4 and $14.5 \%$, respectively, when compared to the 
Table 2. Effect of bee pollen (BP) and bee glue (BG) supplementation on broiler growth performance $(n=5)$

\begin{tabular}{|c|c|c|c|c|c|c|}
\hline \multirow{2}{*}{ Indices } & \multicolumn{4}{|c|}{ Treatments $^{1}$} & \multirow{2}{*}{ SEM } & \multirow{2}{*}{$P$-value } \\
\hline & control & $\mathrm{BP}$ & BG & $\mathrm{BP}+\mathrm{BG}$ & & \\
\hline Initial BW² & 49.5 & 49.3 & 49.6 & 49.2 & - & - \\
\hline Final BW & $1948^{b}$ & $2065^{a}$ & $2049^{a}$ & $2053^{a}$ & 2.317 & 0.027 \\
\hline \multicolumn{7}{|c|}{ Starter period, day $1-21$ day of life } \\
\hline $\mathrm{ADG}^{3}, \mathrm{~g}$ & $32.6^{b}$ & $37.7^{a}$ & $37.5^{\mathrm{a}}$ & $37.3^{\mathrm{a}}$ & 0.102 & 0.025 \\
\hline$A D F I^{4}, g$ & $46.3^{b}$ & $53.4^{\mathrm{a}}$ & $52.9^{a}$ & $53.0^{\mathrm{a}}$ & 0.402 & 0.041 \\
\hline $\mathrm{FCR}^{5}, \mathrm{~g}$ feed $\cdot \mathrm{g}^{-1} \mathrm{BWG}^{6}$ & 1.42 & 1.42 & 1.41 & 1.42 & 0.010 & 0.872 \\
\hline \multicolumn{7}{|c|}{ Finisher period, day $22-42$ day of life } \\
\hline$A D G, g$ & 57.6 & 58.1 & 57.8 & 58.0 & 0.211 & 0.632 \\
\hline $\mathrm{ADFI}, \mathrm{g}$ & 113.8 & 115.2 & 114.8 & 115.1 & 1.201 & 0.924 \\
\hline FCR, $g$ feed $\cdot g^{-1}$ BWG & 1.97 & 1.98 & 1.99 & 1.98 & 0.022 & 0.750 \\
\hline \multicolumn{7}{|l|}{ Overall, $1-42$ day of life } \\
\hline$A D G, g$ & $45.2^{b}$ & $48.0^{\mathrm{a}}$ & $47.6^{\mathrm{a}}$ & $47.7^{\mathrm{a}}$ & 0.401 & 0.032 \\
\hline $\mathrm{ADFI}, \mathrm{g}$ & $80.1^{b}$ & $84.3^{\mathrm{a}}$ & $84.0^{\mathrm{a}}$ & $84.1^{\mathrm{a}}$ & 0.554 & 0.041 \\
\hline$F C R, g$ feed $\cdot g^{-1}$ BWG & 1.77 & 1.76 & 1.77 & 1.76 & 0.025 & 0.232 \\
\hline
\end{tabular}

${ }_{1}^{1}$ treatments: control-basal diet; $B P-$ basal diet $+20 \mathrm{~g} \cdot \mathrm{kg}^{-1}$ of $\mathrm{BP} ; \mathrm{BG}$ - basal diet $+3 \mathrm{~g} \cdot \mathrm{kg}^{-1}$ of BG; $\mathrm{BP}+\mathrm{BG}-$ basal diet $+20 \mathrm{~g} \cdot \mathrm{kg}^{-1}$ of $\mathrm{BP}+3 \mathrm{~g} \cdot \mathrm{kg}^{-1}$ of $\mathrm{BG} ;{ }^{2} \mathrm{BW}$ - body weight; ${ }^{3} \mathrm{ADG}$ - average daily gain; ${ }^{4} \mathrm{ADFI}$ - average daily feed intake; ${ }^{5} \mathrm{FCR}$ - feed conversion ratio; ${ }^{6} \mathrm{BWG}$ - body weight gain; ${ }^{a b}$ means with different superscipts within a row are significantly different at $P \leq 0.05$

Table 3. Effect of bee pollen (BP) and bee glue (BG) supplementation on organs weights in relation to body weight (BW) at 42 day of life

\begin{tabular}{|c|c|c|c|c|c|c|}
\hline \multirow{2}{*}{$\begin{array}{l}\text { Relative organ } \\
\text { weight, } \mathrm{g} \cdot 100 \mathrm{~g}^{-1} \mathrm{BW}\end{array}$} & \multicolumn{4}{|c|}{ Treatments $^{1}$} & \multirow{2}{*}{ SEM } & \multirow{2}{*}{$P$-value } \\
\hline & control & $\mathrm{BP}$ & BG & $B P+B G$ & & \\
\hline Pancreas & 0.22 & 0.24 & 0.23 & 0.22 & 0.012 & 0.871 \\
\hline Liver & 1.96 & 2.00 & 1.97 & 1.98 & 0.131 & 0.285 \\
\hline Heart & 0.54 & 0.56 & 0.54 & 0.55 & 0.056 & 0.654 \\
\hline Gizzard & 1.42 & 1.39 & 1.40 & 1.41 & 0.014 & 0.311 \\
\hline Intestine & 2.58 & 2.61 & 2.57 & 2.26 & 0.035 & 0.767 \\
\hline Spleen & $0.15^{b}$ & $0.21^{\mathrm{a}}$ & $0.19^{a}$ & $0.20^{a}$ & 0.013 & 0.045 \\
\hline Bursa & $0.16^{b}$ & $0.20^{\mathrm{a}}$ & $0.18^{a}$ & $0.19^{a}$ & 0.017 & 0.022 \\
\hline
\end{tabular}

${ }^{1}$ see Table 2; each value represents the mean of 10 observations ( 5 replicates $\times 2$ birds per replicate); ${ }^{a b}$ means with different superscipts within a row are significantly different at $P<0.05$

control diet. For the overall period, the inclusion of BP into the diet increased $(P<0.05)$ ADG and ADFI by 6.2 and $5.2 \%$, respectively, and ADG and ADFI of BG group were 5.3 and $4.9 \%$ higher $(P<0.05)$ than in the control group, respectively. The ADG and ADFI obtained in the group fed diet with combined supplementation (BP + BG) were increased $(P<0.05)$ by 5.5 and $5.0 \%$, respectively, in comparison to control group.
On the 42 day of life the addition of BP and BG into chicken feed increased the relative weight of spleen and bursa when compared to the control group $(P<0.05)$ (Table 2$)$. There was observed no influence of examined addictives on pancreas, liver, heart, gizzard and intestine relative weight.

The blood lymphocytes (L) and heterophils (H) levels were not statistically different between groups, but $\mathrm{H}$ :L ratio was lower $(P<0.05)$ in chickens fed supplemented diets in comparison to the control group by $9.1 \%, 12.1 \%$ and $15.2 \%$ for $\mathrm{BP}, \mathrm{BG}$ and $\mathrm{BP}+\mathrm{BG}$ groups, respectively (Table 4).

A significant reduction $(P<0.05)$ was recorded in the creatine kinase (CK) level in the breast muscle for BP and BG groups as compared to the control group (Figure 1), but the effect of combined supplementation (BP + BG) was insignificant for CK level in comparison to control birds. Real-time PCR analysis showed that dietary treatments downregulated the HSP70 gene expression with a significant difference $(P<0.05)$ when compared to the control group (Figure 2).

Table 4. Effect of bee pollen (BP) and bee glue (BG) supplementation on blood heterophil $(H)$ and lymphocyte $(H)$ concentrations and $H: L$ ratio in broilers ${ }^{1}$

\begin{tabular}{|c|c|c|c|c|c|c|}
\hline \multirow{2}{*}{ Item } & \multicolumn{4}{|c|}{ Treatments $^{2}$} & \multirow{2}{*}{ SEM } & \multirow{2}{*}{$P$-value } \\
\hline & control & $\mathrm{BP}$ & $B G$ & $\mathrm{BP}+\mathrm{BG}$ & & \\
\hline Heterophils $\left(\mathrm{H} ; \times 10^{9} \cdot \mathrm{I}^{-1}\right)$ & 33.8 & 32.6 & 31.9 & 30.8 & 0.414 & 0.465 \\
\hline Lymphocytes $\left(\mathrm{L} ; \times 10^{9} \cdot \mathrm{I}^{-1}\right)$ & 101.5 & 109.4 & 109.6 & 108.7 & 1.132 & 0.383 \\
\hline $\mathrm{H}: \mathrm{L}$ ratio & $0.33^{\mathrm{a}}$ & $0.30^{\mathrm{b}}$ & $0.29^{b}$ & $0.28^{b}$ & 0.022 & 0.032 \\
\hline
\end{tabular}

${ }^{1}$ see Table 2; each value represents the mean of 10 observations ( 5 replicates $\times 2$ birds per replicate); ab means with different superscipts within a row are significantly different at $P<0.05$ 


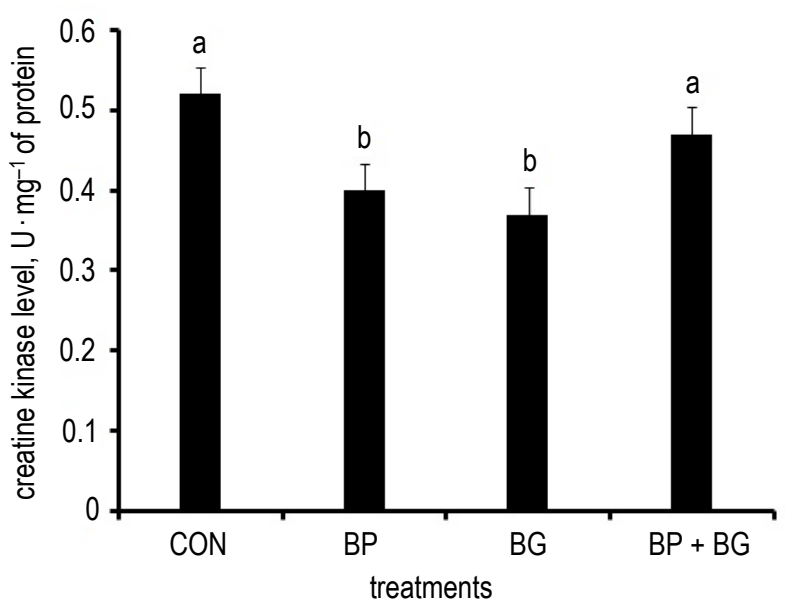

Figure 1. Effect of bee pollen (BP) and bee glue (BG) supplementation on creatine kinase $\left(\mathrm{U} \cdot \mathrm{mg}^{-1}\right.$ of protein) level of chicken breast muscle. Mean values represent the average of 5 replicates of 4 groups $(n=5)$. Values are means $\pm S E M ;{ }^{\text {ab }}$ - bars with different superscripts are significantly different $(P<0.05)$. Treatments: CON - basal diet; $\mathrm{BP}$ - basal diet $+20 \mathrm{~g} \cdot \mathrm{kg}^{-1}$ of $\mathrm{BP} ; \mathrm{BG}-$ basal diet $+3 \mathrm{~g} \cdot \mathrm{kg}^{-1}$ of $\mathrm{BG}$; $\mathrm{BP}+\mathrm{BG}-$ basal diet $+20 \mathrm{~g} \cdot \mathrm{kg}^{-1}$ of $\mathrm{BP}+3 \mathrm{~g} \cdot \mathrm{kg}^{-1}$ of $B G$

Table 5. Effect of bee pollen (BP) and bee glue (BG) supplementation on intestinal morphometery at 42 day of life

\begin{tabular}{|c|c|c|c|c|c|c|}
\hline \multirow{2}{*}{ Item } & \multicolumn{4}{|c|}{ Treatments $^{1}$} & \multirow{2}{*}{\multicolumn{2}{|c|}{ SEM $P$-value }} \\
\hline & control & $\mathrm{BP}$ & $B G$ & $\mathrm{BP}+\mathrm{BG}$ & & \\
\hline \multicolumn{7}{|l|}{ Duodenum } \\
\hline villus length,um & 1345 & 1348 & 1345 & 1349 & 1.4 & 0.780 \\
\hline crypt depth, $\mu \mathrm{m}$ & 185 & 187 & 187 & 186 & 0.7 & 0.362 \\
\hline villus:crypt ratio & 7.27 & 7.21 & 7.19 & 7.25 & 0.01 & 0.455 \\
\hline \multicolumn{7}{|l|}{ Jejunum } \\
\hline villus length, $\mu \mathrm{m}$ & $1165^{b}$ & $1224^{a}$ & $1175^{b}$ & $1167^{b}$ & 1.6 & 0.027 \\
\hline crypt depth, $\mu \mathrm{m}$ & $158^{b}$ & $164^{a}$ & $161^{b}$ & $159^{b}$ & 1.1 & 0.035 \\
\hline villus:crypt ratio & $7.37^{\mathrm{b}}$ & $7.46^{\mathrm{a}}$ & $7.30^{\mathrm{b}}$ & $7.34^{b}$ & 0.05 & 0.024 \\
\hline \multicolumn{7}{|l|}{ lleum } \\
\hline villus length, $\mu \mathrm{m}$ & 845 & 847 & 841 & 846 & 1.4 & 0.131 \\
\hline crypt depth, $\mu \mathrm{m}$ & 165 & 166 & 165 & 164 & 1.8 & 0.322 \\
\hline villus:crypt ratio & 5.12 & 5.10 & 5.10 & 5.16 & 0.06 & 0.373 \\
\hline
\end{tabular}

${ }^{1}$ see Table 2; each value represents the mean of 10 observations ( 5 replicates $\times 2$ birds per replicate); ab means with different superscipts within a row are significantly different at $P<0.05$

Dietary treatments did not have significant effect on the duodenal morphology (Table 5). In birds fed diet supplemented with BP, the villus length, crypt depth and villus length:crypt depth ratio in the jejunum were increased $(P<0.05)$ in comparison to those fed control, BG and BP + BG diets. Dietary addition of $\mathrm{BP}$ and $\mathrm{BG}$ (alone or together) did not have a significant effect on the morphometric indices in the ileum segment.

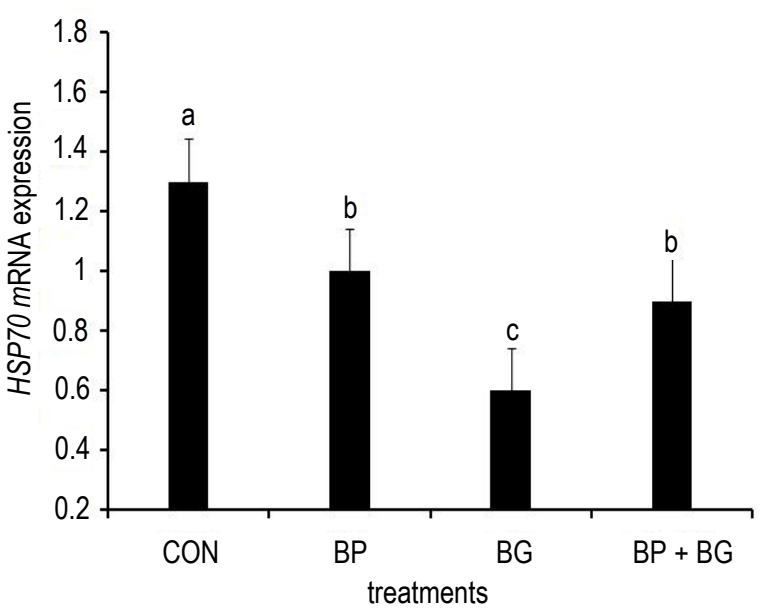

Figure 2. Effect of bee pollen (BP) and bee glue (BG) supplementation on relative values of HSP70 mRNA expression in chicken breast muscle. Mean values represent the average of 5 replicates of 4 groups $(n=5)$. Values are means \pm SEM; ${ }^{\text {ab }}-$ see Figure 1 . Treatments: see Figure 1

\section{Discussion}

The mode of action of bee glue (BG) and bee pollen (BP) may be not only due to a strong effect of antibacterial action, but also due to the presence of micronutrients with positive effects on bird health and metabolism (Viuda-Martos et al., 2008). It has been revealed that the positive effects of dietary BP on broiler growth could be related to the high contents of BP nutrients. Essential amino acids, polyunsaturated fatty acids (PUFA), and some trace elements (Šarić et al., 2009) can be easily absorbed as BP components (Markham et al., 1996). The current study indicated that dietary inclusion of $\mathrm{BP}$ and BG (alone or together) improved the broiler performance when compared to the unsupplemented diet in the starter stage. The insignificant effects of dietary supplementations during finisher period might be due to the heat stress effect on bird performance. However, weight gain and feed consumption of broilers exposed to a high ambient temperature were unaffected by dietary treatments. The results also indicate that BP and BG could be effective as additives improving the productive performance of broiler chickens reared in heat stress conditions. These findings confirm those reported by Attia et al. (2011) who indicated that BP and BG can be use in poultry feeds as natural growth promoters. Also, Eyng et al. (2014) indicated that addition of BP to drinking water increased body weight gain and feed consumption in young broiler chickens. 
Quinteiro-Filho et al. (2010), who investigated the influence of the heat stress on the broiler bursa of Fabricius and spleen, pointed out that stress induces lymphoid organs atrophy and reduction in bursa weight. Spleen, known as the main immune organ, plays an important role in the body defense against microorganisms (Akter et al., 2006). The relative lymphoid organs weight is used to judge the immune status of broiler chickens. In the present study, the addition of BP and BG to the diets increased relative weight of bursa of Fabricius and spleen of broiler chickens. Also Wang et al. (2007) found that the spleen and bursa of Fabricius were heavier in broilers fed diets with the addition of BP. Currently, there is a lack of sufficient literature to explain the effects of BP and BG on lymphoid tissues in heat stress conditions. The increase in relative weight of spleen and bursa in the BP and BG supplemented diets may be an indication of the immune-booster effect of these additives. BP and BG are rich in nutrients, which promote faster proliferation and differentiation of the birds immune system cells (Sforcin, 2007; Šarić et al., 2009).

Reports on the effect of BP and BG supplementation on haematological parameters are very scarce. It has been recognized that heterophil:lymphocyte $(\mathrm{H}: \mathrm{L})$ ratio may be treated as stress index in birds and is known to be increased due to the effect of ambient stress over long term including heat stress (Vleck et al., 2000). The current results obtained for H:Lratio showed that dietary addition of $\mathrm{BP}, \mathrm{BG}$ and $\mathrm{BP}+\mathrm{BG}$ improved the tolerance to permanent high ambient temperature. Moreover, decrease in heterophil count is also a positive indication of improved action of dietary antioxidants against heat stress, as indicated in our study. In general, the obtained immunological activities in the current research possibly indicate that $\mathrm{BP}$ and $\mathrm{BG}$ can alleviate the negative effects of heat stress in broilers.

The results of the present study indicate that creatine kinase (CK) level in broiler breast muscles was decreased, which probably is an indication of improving effects of dietary $\mathrm{BP}$ and $\mathrm{BG}$ against persistent heat stress. This result is in agreement with the studies of Sahin et al. (2008) and Patra et al. (2011) who concluded that dietary natural antioxidants are the first strategy against the unpleasant consequences of heat stress on the quality of poultry meat. Moreover, the results revealed that the combination of BP and BG did not have a significant effect on CK level. Hence, the results may suggest that addition of BP or BG into feed could play a role in the decrease of myopathy in broiler chickens that is indicated by the reduced muscular CK level.
Another interesting findings in the current research were the effects of BP and BG supplementations on HSP70 mRNA expression level in the chicken breast muscle. The most important reason for measuring the HSP70 gene expression in different studies is the evidence that support their role not only in high ambient temperature but also in cell death mediated by free radicals and reactive oxygen species (Jacquier-Sarlin et al., 1994). In the current study, the down-regulation of HSP70 mRNA expression by the dietary $\mathrm{BP}, \mathrm{BG}$ and $\mathrm{BP}+\mathrm{BG}$ might be due to functional likeness of BP with oestrogen. This novel finding suggests that an unknown compound of BP and BG might cause a similar effect of that observed for oestrogen on HSP70 mRNA induction through a nutritional mechanism. Bongiovanni et al. (2007) investigated the effects of natural antioxidants against stressors, such us heat, and concluded that dietary inclusion of flavonoids may have a protective effect against acute heat stress. Nevertheless, further studies are necessary to investigate the effect of the flavonoids on down-regulation of HSP70 mRNA and their antioxidant effect in broilers reared under heat stress.

Jia et al. (2010) reported that both villus length and crypt depth are important indicators of the digestive health of birds and directly attributed to the absorptive capacity of the mucous membrane. In addition, higher villus:crypt ratio suggests higher digestive and absorptive capacities in the jejunum (Xu et al., 2009). Thus, the increased ratios obtained here can be attributed to the beneficial effect of BP in controlling proliferation of pathogenic bacteria and avoiding possible damage to the intestinal mucosa, which could result in reduced dimensions of the villi. Thus, addition of dietary BP to the diet may stimulate the digestive and absorptive functions of broiler chickens and may be helpful in explaining the improvement in average daily gain and average daily feed intake observed during the starter stage.

\section{Conclusions}

The results indicate the protective effects of bee pollen (BP) and bee glue (BG) against persistent high ambient temperature effects in broiler chickens. It could be concluded that the dietary use of BP and BG as a feed additives may offer a nutritional strategy in broiler farming to overcome the disadvantageous effects of heat stress in broiler.

\section{References}

Akter S.H., Khan M.Z.I., Jahan M.R., Karim M.R., Islam M.R., 2006. Histomorphological study of the lymphoid tissues of broiler chickens. Bangl. J. Vet. Med. 4, 87-92 
Attia Y.A., Abd Al-Hamid A.E., Ibrahim M.S., Al-Harthi M.A., Bovera F. Elnaggar A.S., 2014. Productive performance, biochemical and hematological traits of broiler chickens supplemented with propolis, bee pollen, and mannan oligosaccharides continuously or intermittently. Livest. Sci. 164, 87-95

Attia Y.A., Al-Hanoun A., Bovera F., 2011. Effect of different levels of bee pollen on performance and blood profile of New Zealand White bucks and growth performance of their offspring during summer and winter months. J. Anim. Physiol. Anim. Nutr. 95, $17-26$

Bankova V.S., De Castro S.L., Marcucci M.C., 2000. Propolis: recent advances in chemistry and plant origin. Apidologie 31, 3-15

Banskota A.H., Tezuka Y., Adnyana I.K., Midorikawa K., Matsushige K., Message D., Huertas A.A.G., Kadota S., 2000. Cytotoxic, hepatoprotective and free radical scavenging effects of propolis from Brazil, Peru, the Netherlands and China. J. Ethnopharmacol. 72, 239-246

Bongiovanni G.A., Soria E.A., Eynard A.R., 2007. Effects of the plant flavonoids silymarin and quercetin on arsenite-induced oxidative stress in $\mathrm{CHO}-\mathrm{K} 1$ cells. Food Chem. Toxicol. 45 , 971-976

Chiang W., Booren A., Strasburg G., 2008. The effect of heat stress on thyroid hormone response and meat quality in turkeys of two genetic lines. Meat Sci. 80, 615-622

Eyng C., Murakami A.E, Duarte C.R.A., Santos T.C., 2014. Effect of dietary supplementation with an ethanolic extract of propolis on broiler intestinal morphology and digestive enzyme activity. J. Anim. Physiol. Anim. Nutr. 98, 393-401

Hao Y., Gu X.H., Wang, X.L., 2012. Overexpression of heat shock protein 70 and its relationship to intestine under acute heat stress in broilers: 1. Intestinal structure and digestive function. Poultry Sci. 91, 781-789

Jacquier-Sarlin M.R., Fuller K., Dinh-Xuan A.T., Richard M.-J., Polla B.S., 1994. Protective effects of hsp70 in inflammation. Experientia 50, 1031-1038

Jia G., Yan J.-Y., Cai J.-Y., Wang K.-N., 2010. Effects of encapsulated and non-encapsulated compound acidifiers on gastrointestinal $\mathrm{pH}$ and intestinal morphology and function in weaning piglets. J. Anim. Feed Sci. 19, 82-93

Kamboh A.A, Hang S.Q., Bakhetgul M., Zhu W.-Y., 2013. Effects of genistein and hesperidin on biomarkers of heat stress in broilers under persistent summer stress. Poultry Sci. 92, 2411-2418

Luna L.G. (Editor), 1968. Manual of Histologic Staining Methods of the Armed Forces Institute of Pathology. Blackiston Division, McGraw-Hill, NY (USA)

Markham K.R., Mitchell K.A., Wilkins A.L., Daldy J.A., Lu Y., 1996. HPLC and GC-MS identification of the major organic constituents in New Zealand propolis. Phytochemistry 42, 205-211
NRC, 1994. Nutrient Requirements of Poultry. $9^{\text {th }}$ Edition. National Academic Press. Washington DC (USA)

Patra T., Pati P.K., Mohapatra A.K., 2011. Study on carcass quality of coloured broiler chicks supplemented with vitamin $E$ and $C$ during summer stress. SAARC J. Agric. 9, 123-132

Quinteiro-Filho W.M., Ribeiro A., Ferraz-de-Paula V., Pinheiro M.L., Sakai M., Sá L.R.M., Ferreira A.J.P., Palermo-Neto J., 2010. Heat stress impairs performance parameters, induces intestinal injury, and decreases macrophage activity in broiler chickens. Poultry Sci. 89, 1905-1914

Sahin N., Orhan C., Tuzcu M., Sahin K., Kucuk O., 2008. The effects of tomato powder supplementation on performance and lipid peroxidation in quail. Poultry Sci. 87, 276-283

SAS, 2006. Statistical Analysis Systems User's Guide. 9.1 $1^{\text {th }}$ Edition. SAS Institute Inc., Cary, NC, USA

Seven P.T., 2008. The effects of dietary Turkish propolis and vitamin C on performance, digestibility, egg production and egg quality in laying hens under different environmental temperatures. Asian-Aust. J. Anim. Sci. 21, 1164-1170

Sforcin J.M., 2007. Propolis and the immune system: a review. J. Ethnopharmacol. 113, 1-14

Sforcin J.M., Bankova V., 2011. Propolis: Is there a potential for the development of new drugs? J. Ethnopharmacol. 133, 253-260

Šarić A., Balog T., Sobočanec S. et al., 2009. Antioxidant effects of flavonoid from Croatian Cystus incanus L. rich bee pollen. Food Chem. Toxicol. 47, 547-554

Viuda-Martos M., Ruiz-Navajas Y., Fernández-López J., Pérez-Álvarez J.A., 2008. Functional properties of honey, propolis, and royal jelly. J. Food Sci. 73, R117-R124

Vleck C.M., Vertalino N., Vleck D., Bucher T.L., 2000. Stress, corticosterone, and heterophil to lymphocyte ratios in free-living Adélie Penguins. Condor 102, 392-400

Vynograd N., Vynograd I., Sosnowski Z., 2000. A comparative multicentre study of the efficacy of propolis, acyclovir and placebo in the treatment of genital herpes (HSV). Phytomedicine 7, $1-6$

Wang J., Li S., Wang Q., Xin B., Wang H., 2007. Trophic effect of bee pollen on small intestine in broiler chickens. J. Med. Food. 102, 276-280

Xu X., Sun L., Dong J., Zhan H., 2009. Breaking the cells of rape bee pollen and consecutive extraction of functional oil with supercritical carbon oxide. Innov. Food Sci. Emerg. Technol. 10, 42-46

Yu B., Tsai C.C., Hsu J.C., Chiou P.W.S., 1998. Effect of different sources of dietary fibre on growth performance, intestinal morphology and caecal carbohydrases of domestic geese. Brit. Poultry Sci. 39, 560-567 